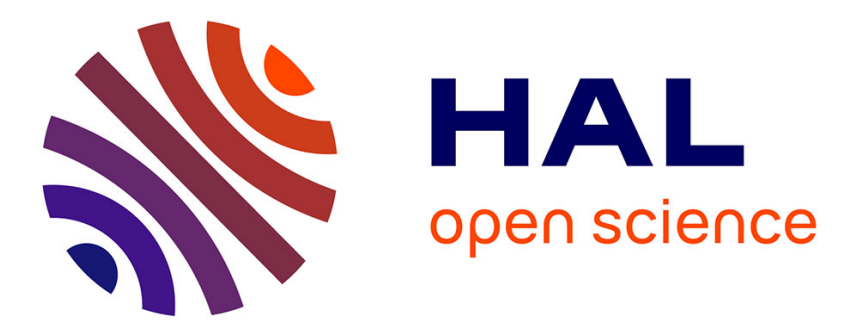

\title{
Comparative curing kinetics study of high char yield formaldehyde- and terephthalaldehyde-phenolic thermosets
}

Lérys Granado, Romain Tavernier, Gabriel Foyer, Ghislain David, Sylvain Caillol

\section{To cite this version:}

Lérys Granado, Romain Tavernier, Gabriel Foyer, Ghislain David, Sylvain Caillol. Comparative curing kinetics study of high char yield formaldehyde- and terephthalaldehyde-phenolic thermosets. Thermochimica Acta, 2018, 667, pp.42-49. 10.1016/j.tca.2018.06.013 . hal-01854078

\section{HAL Id: hal-01854078 https://hal.science/hal-01854078}

Submitted on 15 May 2020

HAL is a multi-disciplinary open access archive for the deposit and dissemination of scientific research documents, whether they are published or not. The documents may come from teaching and research institutions in France or abroad, or from public or private research centers.
L'archive ouverte pluridisciplinaire HAL, est destinée au dépôt et à la diffusion de documents scientifiques de niveau recherche, publiés ou non, émanant des établissements d'enseignement et de recherche français ou étrangers, des laboratoires publics ou privés. 


\section{Comparative curing kinetics study of high char yield 2 formaldehyde- and terephthalaldehyde-phenolic thermosets}

3 Lérys Granado ${ }^{1}$, Romain Tavernier ${ }^{1}$, Gabriel Foyer ${ }^{2}$, Ghislain David ${ }^{1}$, Sylvain Caillol ${ }^{1 *}$

$4{ }^{1}$ Institut Charles Gerhardt UMR 5253, CNRS, Université de Montpellier, ENSCM, 240, Avenue Professeur

5 Emile Jeanbrau, 34296 Montpellier, France

$6 \quad{ }^{2}$ ArianeGroup, Rue de Touban, 33185 Le Haillan, France.

$7 \quad *$ Corresponding author: sylvain.caillol@enscm.fr

\section{$8 \quad$ Abstract}

9 Phenol-Formaldehyde (PF) resoles exhibit excellent thermal properties, high temperature degradation and high char yield. The formaldehyde can be replaced by terephthalaldehyde

11 (TPA), a non-toxic aromatic dialdehyde. The thermal performances of phenol-TPA (PTPA) resole are very interesting for further development and industrialization. The present investigation presents for the first time a thermo-kinetics study of curing of PTPA, in comparison with a commercial PF resole. Non-isothermal, at constant heating rates DSC experiments are performed on both resoles. PF shows one single exothermic peak, whereas PTPA exhibits two DSC peaks, suggesting a two-step curing mechanism which appears to be conversion-dependent. In addition, isoconversional analysis is used to elucidate the activation energies as a function of the degree of curing. Differential Friedman and integral Vyazovkin methods are considered for computations, giving equivalent results. Furthermore, the whole kinetic triplets $(E, A, f)$ is elucidated for both resoles with Sestak-Berggren model fitting. Finally, isothermal isoconversional predictions are compared to experimental data.

- The curing kinetics of a new formaldehyde-free resole is compared to PF resole

- Isoconversional analyses are employed to determine activation energy values

- Sestak-Berggren model is used to fit the data, elucidating the kinetic triplet

- Isothermal predictions are consistent with experimental data 
Resoles; Phenol; Terephthalaldehyde; Curing kinetics; DSC; Isoconversional analysis.

\section{Introduction}

Phenolic thermosets are extensively used as binders in composites in many fields of applications such as microelectronics, wood industry, aerospace etc. [1,2]. These phenolic networks (PF) are crosslinked polymers obtained by reaction between phenol and formaldehyde. The mechanisms of synthesis of those PF, which involves two successive steps, are perfectly described in the literature [3-14]. The first reaction consists in the addition of formaldehyde onto phenol (pre-polymerization). Then, during curing, the crosslinking is achieved by condensation of methylol moieties, releasing water. Two main routes are used to produce high crosslinking density (Fig. 1). Novolacs are synthesized in acidic catalytic conditions, whereas resoles are obtained under alkaline conditions. Moreover, the resoles could reach high crosslinking and aromatic density without adding further crosslinking agent. Such high aromatic densities are required to achieve the excellent thermal resistance of resoles (high char yields) [15-19].

\section{Insert Fig 1 (see captions in the end of the manuscript)}

However, phenol and formaldehyde are rather toxic and classified as carcinogenic, mutagenic and reprotoxic (CMR) substances. Especially formaldehyde is highly volatile and is classified CMR 1B by the European Chemical Agency. Therefore there is sufficient evidence to demonstrate its carcinogenicity on mammals and as a consequence, to presume carcinogenicity for humans [20]. Thus, efforts have been focused on the substitution of the formaldehyde in phenolic resins. Several challenging issues were reported, such as (i) poor reactivity of higher molar mass aldehyde compounds [21], (ii) enolisable aldehydes are prone to side-reactions [22] and (iii) aliphatic aldehydes significantly reduce aromatic density and thus the thermal properties [23].

In a previous study, the reactivity of several bio-based, non-toxic and non-CMR dialdehydes with phenol was evaluated [24]. Among them, terephthalaldehyde showed the best reactivity, which could be explained by the presence of the second aldehyde in para-position. Indeed, the second aldehyde acts as an electron-withdrawing group and thus enhances the reactivity with phenol. 
Terephthalaldehyde can be synthesized by the oxidation in vapor phase of para-xylene [25] which is also the key intermediate to obtain terephthalic acid, mainly used for the production of polyethylene terephthalate (PET). Bio-based routes to para-xylene have been developed in order to access to fully bio-based PET, as a consequence, terephthalaldehyde is being considered as a potentially bio-based building block [26].

In addition, the synthesized phenol-terephthalaldehyde (PTPA) resole showed a better thermal resistance and char yield compared to conventional PF (Table 1). The PTPA thermosets show highly crosslinked networks (networks totally insoluble in organic solvents with a low swelling index). Furthermore, the rheological behavior of both PF and PTPA pre-polymers are comparable. Such preliminary results are very promising for further development of formaldehyde-free networks and composites, with an excellent thermal resistance and a high char yield.

The manufacturing process of phenolic thermosets and composites is typically performed in three steps: (i) synthesis of the pre-polymer (corresponding to the addition reaction in PF), (ii) shaping (i.e. impregnation for composites) and pre-curing stage, within which partial hardening of the matrix is achieved (e.g. pre-pregs) and (iii) post-curing stage which allows complete crosslinking of the matrix. Noteworthy, the degree of curing drives all chemical and physical parameters (e.g. rheological behavior, chemical resistance...). It is therefore of prime importance to accurately control the curing kinetics all along the manufacturing process of final piece.

The curing of phenolic thermosets is a thermally-activated process. Previous studies report on the study of PF curing kinetics based on differential scanning calorimetry (DSC) experimental data. In addition, several computation approaches have been studied to provide maximum information on the kinetic parameters of PF curing such as model-free [27-32] and model fitting kinetics [33]. Among them, the model-free kinetics approach, isoconversional analysis, is known to offer accurate description of the kinetics from a short experimental dataset, with a systematic and rather simple calculation process [34].

In the present paper, we suggest studying the curing kinetics of an innovative formaldehydefree and potentially bio-based phenolic thermoset with high char yield, i.e. phenolterephthalaldehyde resole, in comparison with a commercially available PF resole. Hence, the curing kinetics data are provided from non-isothermal DSC experiments, at different linear heating rates, following the recommendations found in literature [35]. In addition, kinetic 
modellings are performed using isoconversional analysis. Hence, quantitative kinetic data of phenol-terephthalaldehyde curing are presented. Finally, the predictability performances of the kinetics parameters are evaluated.

\section{Insert Fig 2}

\section{Insert Table 1}

\section{Experimental Section}

\section{Materials}

The phenol was purchased from Alfa-Aeasar. The terephthalaldehyde and the sodium hydroxide were purchased from Sigma-Aldrich. PF resole was a commercially available prepolymer. The reactants and the solvent were 98-99\% pure and used without further purification. Pre-polymers were stored at $-18{ }^{\circ} \mathrm{C}$ to avoid unwanted crosslinking.

\section{Pre-polymerization synthesis}

Phenol (1 eq.), sodium hydroxide (0.04 eq.) aqueous solution (50 wt.\%) and ethanol (14 wt.\%) were introduced into a two-necked flask. A condenser, a magnetic stirrer and a silicon oil bath were used. The temperature was set at $100{ }^{\circ} \mathrm{C}$. When the mixture was on temperature and homogeneous, terephthalaldehyde ( 0.4 eq.) was added $\left(t_{0}\right)$. The reaction was performed for 4 hours and monitored by ${ }^{1} \mathrm{H}$ nuclear magnetic resonance spectroscopy. The color changed from orange to black between 1 and $2 \mathrm{~h}$ of reaction. It is important to stress than after the pre-polymerization, only the first aldehyde functionality of TPA has reacted, whereas the second aldehyde groups mostly remain unreacted.

\section{DSC}

The DSC-3 F200 (Netzsch) equipped with an intra-cooler module is used to carry out the calorimetric study, with nitrogen atmosphere (at $50 \mathrm{~mL} / \mathrm{min}$ ). The temperature and sensibility are calibrated with biphenyl, indium, bismuth and $\mathrm{CsCl}$ highly pure standards, at $10{ }^{\circ} \mathrm{C} / \mathrm{min}$. To avoid interfering endothermic signal of solvent and water evaporations, high pressure stainless steel pans and lids (Netzsch) are used (maximum pressure of $100 \mathrm{MPa}$ ). They are sealed with golden seal at $3 \mathrm{~N} \cdot \mathrm{cm}$. The samples are weighted on a $10^{-5} \mathrm{~g}$ precise analytical balance (between 12.00 and $20.00 \mathrm{mg}$ ). The sample mass demonstrates no influence on the total enthalpy of the reaction. Each pan + sample is weighed before and after analysis to be 
sure that no evaporation has disturbed the measurement. In any case, the temperature considered is the sample temperature. The curing reaction is monitored by DSC at the heating rates: $\beta=5,7.5,10,12.5$ and $15^{\circ} \mathrm{C} / \mathrm{min}$, for both PF and PTPA networks.

\section{Implementation of computations}

The Vyazovkin method code is implemented using Python software, using the modules Scipy and Numpy. Integral functions are calculated using scipy.integral.quad built-in function, with an increment of $\Delta \alpha=0.01$. The Friedman method ( $\Delta \alpha=0.02$ as increment) and non-linear model-fitting $(\Delta \alpha=0.01)$ are used with the help of Origin software, using damped leastsquares algorithm (Levenberg-Marquardt), with a convergence criterion of $\chi^{2}<10^{-9}$ and a maximum iteration number of 400 , without any weighing of the data. For the model-fitting approach, multivariate $(\alpha, T)$ non-linear fitting is performed on reaction rate vs. degree of curing curves. All heating rate curves associated to one reaction are simultaneously fitted providing a maximum consistency (for this reason fitted curved may deviate from experimental data at some points). All the presented computations are tested with simulated data, giving consistent results.

\section{Theoretical background}

\section{Conversion calculation}

The degree of curing $(\alpha)$ is assumed to be directly proportional to the released heat, measured in DSC:

$$
\alpha(t, T)=\frac{\Delta H_{t, T}}{\Delta H_{T O T A L}}
$$

where $\Delta H_{t, T}=\int_{0}^{t} \dot{q}(t, T) d t$ is the cumulative released heat of reaction at the time $t$ and curing temperature $T$, as time integral of the instantaneous heat flow $(\dot{q}(t, T))$, and $\triangle H_{T O T A L}$ is the total enthalpy of the reaction determined non-isothermally (average of 5 measurements). The zero degree of curing $(\alpha=0)$ corresponds to the pre-polymer.

\section{Principles of isoconversional analyses}

The isoconversional analysis is focused in the determination of the activation energy of a chemical conversion (i.e. crosslinking). Isoconversional analysis is a powerful tool to determine the activation energy of a thermally activated reaction. This analysis does not 
148 require identifying the reaction model and is therefore usually called model-free kinetic 149 method. This analysis relies on the isoconversional principle: "the reaction rate at constant 150 extent of conversion is only a function of temperature" [34]. In other word, the reaction 151 mechanisms are not affected by the temperature program.

152 It is based on the variable separation (conversion, $\alpha$, and temperature, $T$ ), leading to the 153 general equation of the kinetics:

$$
\frac{d \alpha}{d t}=k(T) \cdot f(\alpha)
$$

155 where $d \alpha / d t$ is the reaction rate, $k$ is the rate constant and $f$ is a function of the conversion 156 (representing of the reaction mechanisms). The rate constant is assumed to be described by 157 the Arrhenius equation:

$$
k(T)=A \cdot \mathrm{e}^{-\frac{E}{R T}}
$$

where $A$ is the pre-exponential factor, $E$ the activation energy, $R$ the gas constant and $T$ the temperature.

The isoconversional principle leads to the following equation:

$$
\left[\frac{\partial \ln (d \alpha / d t)}{\partial T^{-1}}\right]_{\alpha}=\left[\frac{\partial \ln (k(T))}{\partial T^{-1}}\right]_{\alpha}+\left[\frac{\partial \ln (f(\alpha))}{\partial T^{-1}}\right]_{\alpha}
$$

163 Because $f(\alpha)$ is constant ( $\alpha=$ constant), this equation leads to the fundamental expression of 164 isoconversional analysis:

$$
\left[\frac{\partial \ln (d \alpha / d t)}{\partial T^{-1}}\right]_{\alpha}=-\frac{E_{\alpha}}{R}
$$

166 where $E_{\alpha}$ is the isoconversional value of the activation energy, i.e. the activation energy for a 167 given value of conversion degree, $\alpha$. Hence, the activation energy is considered as a variable 168 along the transformation process [36].

\section{Friedman method}

170 The method of Friedman is the most common differential isoconversional method and is 171 applicable with its both differential and integral forms. The Friedman's equations arise from 172 the previous analytical equations (2) and (3) without any approximation. Thus, this method is 173 therefore known as the reference [37].

174 The differential equation of Friedman is expressed as follows [37][37][37]: 


$$
\ln \left(\frac{d \alpha}{d t}\right)_{\alpha, i}=\ln \left[A_{\alpha} f(\alpha)\right]-\frac{E_{\alpha}}{R T_{\alpha, i}(t)}
$$

175 where $i$ represents the $\mathrm{i}^{\text {th }}$ temperature program and $T_{\alpha, i}$ is the temperature where the degree of 176 curing, $\alpha$, is reached under the $\mathrm{i}^{\text {th }}$ temperature program (depending on $T$ in the case of non177 isothermal conditions). The $i$ index corresponds to an individual temperature for isothermal programs and to an individual heating rate for linear non-isothermal programs.

\section{Vyazovkin method}

180

$$
\Phi\left(E_{\alpha}\right)=\sum_{i=1}^{n} \sum_{j \neq i} \frac{J_{i}\left(E_{\alpha}, T_{\alpha, i}\right)}{J_{j}\left(E_{\alpha}, T_{\alpha, j}\right)}=n^{2}-n
$$

Vyazovkin method (VA) is a numerical integral method [38,39]. It presents several advantages: it is applicable to both thermogravimetric and integrated DSC data, it takes into account the self-heating/cooling occurring during DSC (deviation of the sample temperature from the imposed $T=t \times \beta$, with $\beta$ the heating rate value), it is applicable to any programs (cooling and multi-step programs) [34]. Moreover, integral method allows avoiding inaccuracies coming from noisy data, which are generally magnified with differential method.

To reach the best accuracy in determining the activation energy, small ranges of conversion degree, $\Delta \alpha$, are considered for the numerical integration. Introducing $g(\alpha)$, the integral form of $f(\alpha)$, we have:

$$
g(x)-g(\alpha-\Delta \alpha)=\int_{\alpha-\Delta \alpha}^{\alpha} \frac{d \alpha}{f(\alpha)}=A_{\alpha} \int_{t_{\alpha-\Delta \alpha}}^{t_{\alpha}} \mathrm{e}^{-\frac{E_{\alpha}}{R T_{\alpha}(t)}} \cdot d t
$$

Considering the principle of isoconversional analysis, it follows:

$$
g(\alpha)-g(\alpha-\Delta \alpha)=A_{\alpha} \cdot J_{1}\left(E_{\alpha}, T_{\alpha, 1}\right)=\cdots=A_{\alpha} \cdot J_{n}\left(E_{\alpha}, T_{\alpha, n}\right)
$$

where $J_{i}\left(E_{\alpha}, T_{\alpha, i}\right)$ is the time integral of the $\mathrm{i}^{\text {th }}$-temperature program $T_{i}(t)$ :

$$
J_{i}\left(E_{\alpha}, T_{\alpha, i}\right)=\int_{t_{\alpha-\Delta \alpha}}^{t_{\alpha}} \mathrm{e}^{-\frac{E_{\alpha}}{R T_{\alpha, i}(t)}} \cdot d t
$$




\section{Results and Discussions}

\section{DSC thermograms}

202 An exothermic signal is recovered during the curing reaction in all cases, as shown in DSC thermograms after linear baseline correction (Fig. 3). As expected, the intensity of the exothermic peak is higher at higher heating rates (as the energy amount released by the reaction per unit of time is larger). Notably, we observed one single peak for PF (Fig.3PF) whereas two peaks are observed for PTPA (Fig.3PTPA). In the latter case, the second peak (towards higher temperature) is always a quarter less intense than the first one. The presence of the two peaks in PTPA networks witnesses two successive steps during the crosslinking mechanism, whereas one single step is observed in PF curing.

210 The maximum of first peak of PTPA is sensibly similar to the PF one (Table 2). The first peak 211 of PTPA crosslinking corresponds to the peak observed with PF. This suggests the same 212 reactivity and kinetics for the PF crosslinking and the reaction occurring during the $1^{\text {st }}$ 213 exothermic peak of PTPA. Furthermore, the maximum of second peak of PTPA is 214 systematically $46 \pm 3{ }^{\circ} \mathrm{C}$ above the first one.

215 The total enthalpy of the reaction is not dependent on heating rates for both formulations 216 (Table 2), suggesting that in both thermosets the temperature profile does not influence the reaction mechanism. The total enthalpy values are respectively $349 \mathrm{~J} / \mathrm{g}$ for PF and $204 \mathrm{~J} / \mathrm{g}$ for 218 PTPA. The low relative standard deviation $(\leq 2-3 \%)$ over 5 measurements shows the good 219 reproducibility of the measurement method. The total enthalpy per gram is lower with PTPA, 220 but compared to molecular weight of typical entities, the total enthalpy gives rather similar 221 values: $68 \mathrm{~kJ} / \mathrm{mol}$ for PF (with $200 \mathrm{~g} / \mathrm{mol}$, for two phenols and one methylene hinge) and 66 $222 \mathrm{~kJ} / \mathrm{mol}$ for PTPA (with $322 \mathrm{~g} / \mathrm{mol}$, for two phenols linked to one TPA).

223 Mechanistic information is readily provided from the thermograms. Hence, different crosslinking mechanisms between PF and PTPA are observed, looking at the shape of the exothermic signal. For PF, the single exothermic peak is assigned to the polycondensation of 226 the methylol groups. These moieties, which have been formed during the addition of 227 formaldehyde on phenolic rings (pre-polymerization stage), mostly condense on unreacted 228 phenolic groups. On the other hand, PTPA curing exhibits a two-step mechanism. The first 229 exothermic peak can be assigned to the condensation reaction of the secondary alcohol (which has been formed during the pre-polymerization stage) onto phenol free positions (mainly 
ortho and para, see reaction I in Fig. 2). The second peak is assigned to the addition of the 232 second aldehyde moiety onto phenol (see reaction II in Fig. 2).

\section{Non-isothermal curing kinetic profiles}

236 The curing kinetic profiles of PF and PTPA are shown in Fig. 4. The degree of curing $(\alpha)$ is 237 plotted as a function of temperature, at different heating rates. Typical sigmoidal-shaped curves are observed. The curves are shifted towards higher temperatures with higher heating rates. Remarkably, the curing kinetics of PF and PTPA are quite similar for $\alpha<0.55$. At $\alpha \sim$ 0.55 , break-in-slopes are observed for PTPA and the curing kinetics start slower than PF. For $\alpha>0.55$, the curing kinetics of PTPA are slower than PF (i.e. toward higher temperatures).

242 This is explained by the two-step mechanism of PTPA curing observed by DSC.

243 The curing reaction rates are calculated as the ratio between the heat flow values and the total 244 reaction heat $\left(\triangle H_{\text {TOTAL}}\right)$. Reaction rates are plotted as a function of the curing degree (insets in 245 Fig. 4). As expected, the higher is the heating rates, the faster is the reaction, for both 246 formulations. However, the reaction curves of PTPA strongly differ from common PF. One 247 step is observed for PF curing, while two steps are obtained for PTPA.

248 Notably, the first step of PTPA curing is centered near a conversion of $\alpha \sim 0.3$, whereas the 249 second one is centered near $\alpha \sim 0.75$, independently of the temperature program. The two250 steps mechanism of PTPA curing is thus conversion-dependent. Because the temperature program does not influence the reaction mechanism, the isoconversional principle is expected to be valid.

\section{Insert Fig 4 PF (upper plot) and PTPA (lower plot)}

\section{Activation energy of curing}

255 The activation energy calculated by isoconversional analysis for PF and PTPA resins is given 256 as a function of the curing degree in Fig. 5. The activation energy, $E_{\alpha}$, for PF and PTPA is 257 ranged between 70 and $80 \mathrm{~kJ} / \mathrm{mol}$. The PF curve of activation energy does not exhibit strong 258 variations with the degree of curing. $E_{\alpha}$ increases from $c a .70 \mathrm{~kJ} / \mathrm{mol}$ to reach a maximum of $25980 \mathrm{~kJ} / \mathrm{mol}$ near $\alpha \sim 0.75$, prior to slightly decrease in the later stage of curing. The PTPA 260 curve shows more variations. The activation energy is relatively constant at low degrees of 
curing $(78 \mathrm{~kJ} / \mathrm{mol}$ for $\alpha<0.3)$, then linearly decreases down to $70 \mathrm{~kJ} / \mathrm{mol}$, for $0.3<\alpha<0.75$.

262 Finally, the activation energy starts increasing slightly for $\alpha>0.75$, which is assigned to increasing uncertainties (such errors probably arise from integration).

264 Two isoconversional methods are tested in parallel: the Vyazovkin (VA) and the Friedman 265 (FR). VA is an integral method - i.e. the activation energy is from integral kinetics profiles 266 (eq. 9-10, Fig. 4), whereas FR is a differential method - i.e. calculations are made from 267 differential curves (Fig. 4 insets). FR method provides elucidation of activation energy with 268 an analytical algebraic formula without any approximation. Arrhenius plots and linear regressions of FR method are shown in Fig. 6. The coefficients of determination (inset in Fig. 6) are satisfying $\left(\mathrm{R}^{2}>0.97\right)$ in the complete range of curing degrees for PF and PTPA (for $\alpha<$ 0.8). For the later, the coefficients of determination decrease down to 0.90 for $\alpha>0.8$, which results in higher uncertainties in activation energy values (represented by broader error-bars in Fig. 5). Remarkably, VA and FR methods give consistent results. The excellent agreement for both VA and FR allows concluding on the accuracy of the obtained results.

The evolution of the activation energy with the degree of curing is informative about the crosslinking process. A rather monotonic shape of $E_{\alpha}$ for PF is observed due to the one-step mechanism of crosslinking, i.e. the condensation of methylol group. The slight increase of $E_{\alpha}$ is assigned to an increase of molecular motion restrictions due to the forming of a threedimensional crosslinked network. Hence, the apparent activation energy increases with the degree of curing due to more intense diffusional potential barrier to overcome. Yet, because this increase remains slight, diffusion phenomena are not expected to drastically slow down the kinetics such as epoxy curing [40,41], for instance. During PF crosslinking, reactive species (i.e. methylol group) are surrounded by free-position in phenol rings at any time, unlike epoxy curing where reactive moieties are carried by dangling chains. In this latter case such reactive moieties may be trapped into the polymer network, which drastically slows down the curing kinetics (diffusion-controlled regime) [45].

On the other hand, the activation energy evolution with $\alpha$ of PTPA is more complex. The experimentally observed two-steps curing can be observed on $E_{\alpha}$ curve, as well. The activation energy plateau value, $E_{\alpha}=78 \mathrm{~kJ} / \mathrm{mol}$ for $\alpha<0.3$, is assigned to the condensation of the secondary alcohol onto phenols (first reaction corresponding to first exothermic peak observed in DSC thermograms). Then during the transient regime, the decrease of $E_{\alpha}$ for $0.3<$ $\alpha<0.75$ is associated to the shift in the curing process mechanism, from the first reaction to

293 the addition onto phenol of the second aldehyde function for the one-fold reacted TPA 
294 (second reaction consistent with the second exothermic peak). The activation energy value 295 associated to the second reaction is determined at $70 \mathrm{~kJ} / \mathrm{mol}$, at $\alpha=0.75$. The slight increase 296 of $E_{\alpha}$ during the later stage of curing is assigned to diffusional restrictions. In overall, the 297 activation energy values of PTPA are similar to the studied PF and other resole $298[27,28,31,33,42]$.

299

\section{Insert Fig 5}

\section{Insert Fig 6 PF (upper plot) and PTPA (lower plot)}

\section{Determination of the kinetic triplet using a model-fitting approach}

In order to provide a full description of the curing kinetics of both resoles (elucidation of the kinetic triplet: $A, E, f(\alpha)$ ), we used the previous results of activation energy to reduce the number of unknown in the model-fitting approach. To model the curing reaction of phenolic resin [33], the truncated Sestak-Breggren (SB) model is used with the following expression [43]:

$$
f(\alpha)=(1-\alpha)^{n} \cdot \alpha^{m}
$$

where $n$ and $m$ are the partial reaction orders. For PF resins, which presents one single step mechanism, following fitting function was employed:

$$
\frac{d \alpha}{d t}=A e^{-\frac{E}{R T(t)}} \cdot(1-\alpha)^{n} \alpha^{m}
$$

with a fixed value of $E=78 \mathrm{~kJ} / \mathrm{mol}$, being the average activation energy value found with previous isoconversional analysis. The fitted curves are displayed in the upper plot of Fig. 7. Small deviations are observed due to simultaneous fitting. Nevertheless, the accordance between fits and experimental data is good $\left(R^{2}>0.99\right)$, leading to a good accuracy on the fitting parameters (Table 3).

On the other hand, the PTPA curing must be analytically described by two successive steps $\left(\frac{d \alpha}{d t}=\sum_{i} k_{i} f_{i}(\alpha)\right.$, with $\left.i=1,2\right)$ [34]. Thus, reaction rate vs. degree of curing curves are first deconvoluted with two Gaussian peak functions ( $\mathrm{R}^{2}>0.97$, global fits are shown in Fig. 7). Then, the deconvoluted peaks are consecutively fitted with equation (12). The activation energies are fixed at $E=78$ and $72 \mathrm{~kJ} / \mathrm{mol}$, for the $1^{\text {st }}$ and $2^{\text {nd }}$ reaction, respectively. SB fits of the deconvoluted curves are rather satisfying $\left(\mathrm{R}^{2}>0.97\right)$, as shown in the lower plot of Fig. 7. 
The pre-exponential factor values vary significantly for PF and both reaction of PTPA (Table 3). Such large variations from resin to resin or along the curing process are noticed when comparing literature values $[30,44,45]$.

The partial reaction order $m$ of $\mathrm{PF}$ is close to 0 (Table 3), concluding in a very low autocatalytic behavior during the curing process. The reaction could therefore be described by a simpler $\mathrm{n}^{\text {th }}$ order model (with a reaction order close to $n=1.1$, which is in line with [33]). In contrast, the $m$ values of PTPA are higher. For the first reaction, the value $m=0.87$ suggests a higher autocatalytic behavior than PF. $n$ of the second PTPA reaction is quite high due to the shift in curing process from $1^{\text {st }}$ to $2^{\text {nd }}$ reaction. By symmetry, $m$ order of second PTPA reaction is also high (due to delayed starting of the $2^{\text {nd }}$ reaction). It is important to stress that these results must be taken carefully because of difficulties in mechanisms elucidation from non-isothermal DSC data, and especially in multi-step mechanism reactions.

\section{Insert Fig 7 PF (upper plot) and PTPA (lower plot)}

\section{Insert Table 3}

\section{Isothermal predictions using isoconversional analysis}

337 One of the most industrially relevant applications of one kinetic analysis is the predictions at 338 both any time and temperature. Hence, one can easily tailor the curing stages (pre- and post339 curing) of the thermoset. Furthermore, predictions allow either confirming or infirming the 340 validity of the kinetics description when compared to experimental data.

341 The time needed to reach a certain $\alpha$ at the isothermal temperature $T_{0}, t_{\alpha, T}$, is calculated with 342 the following equation [46]:

$$
t_{\alpha, \mathrm{T} 0}=\sum_{\alpha} \frac{\hat{J}\left(E_{\alpha, T}\right)}{\exp \left(-\frac{E_{\alpha}}{R T_{0}}\right)}
$$

344 where $\hat{J}\left(E_{\alpha}, T_{\alpha}\right)$ denotes the average of the $J$ functions from all heating rates dataset (rather 345 than an arbitrary single one). Predictions are computed at each isoconversion $(\Delta \alpha=0.01$ 346 increments). Note that only the elucidation of $J$ functions and $E_{\alpha}$ are necessary to compute 347 predictions. To evaluate the predictions accuracy, the simulated curves are compared to 348 experimental results. The isothermal temperature is selected at $T_{0}=160{ }^{\circ} \mathrm{C}$, being the working 349 temperature for curing the commercial PF.

350 Both predicted and experimental isothermal kinetic profiles of PF and PTPA are shown in 351 Fig. 6. Both PF and PTPA isothermal kinetic profiles exhibit a deceleratory shape, typical of 
thermoset crosslinking. Notably the slopes at $\alpha=0$ are similar for PF and PTPA. Then the PF

353 shows a faster isothermal kinetics that of PTPA. The completion is reached within $1 \mathrm{~h}$ for PF, 354 whereas the profile level off near $\alpha \sim 0.9$ for PTPA.

355 The accordance between experimental and predicted curves is excellent for both PF and

356 PTPA. Isoconversional analysis (VA method) provides accurate description of the curing 357 kinetics. Notably, the two-step mechanism of PTPA is well characterized by the variable 358 apparent activation energy along the curing process.

\section{Insert Fig 8}

\section{Conclusions}

361 The present investigation gave insights for the curing behavior of phenol-terephthalaldehyde 362 (PTPA) resoles, which was totally unknown. The curing kinetics of PTPA was compared to a 363 commercial PF resole. The thermosets were probed with non-isothermally DSC, at constant 364 heating rates. Furthermore, computational approaches were performed to get maximum 365 benefits from experimental data. Isoconversional analysis was computed using the differential 366 Friedman (FR) and integral Vyazovkin (VA) methods. The values of activation energy found with both methods were in excellent accordance, allowing concluding on the high accuracy of the presented kinetics data. Then, model-fitting approach was taken using Sestak-Berggren model, to elucidate the kinetic triplet of each reaction.

370 Different curing behaviors were recorded between PF and PTPA. One single step was observed for PF, which corresponded to the polycondensation of methylol moieties releasing water. On the other hand, a two-step mechanism was observed for PTPA. The first was assigned to the polycondensation of secondary alcohols (formed during the first addition of TPA on phenol), whereas the second peak was assigned to the addition of the second aldehyde moiety of TPA onto phenol. Further investigations are ongoing and will be reported

\section{6 elsewhere.}

377 In conclusion, despite different crosslinking mechanisms were observed for PF and PTPA, the 378 curing kinetic parameters showed rather similar values. Finally, isoconversional analysis 379 provided sufficient accurate description of the kinetics, as attested with the good correlation 380 between isothermal predictions and experimental data. The generated kinetics data will be of 381 a precious help for both future development and engineering of PTPA resins or completing mechanistic elucidations of innovative resoles. 


\section{References}

384 [1] Hirano K, Asami M. Phenolic resins-100 years of progress and their future. React Funct Polym 2013;73:256-69. doi:10.1016/j.reactfunctpolym.2012.07.003.

[2] Takeichi T, Furukawa N. Epoxy Resins and Phenol-Formaldehyde Resins. Polym. Sci. A Compr. Ref., Elsevier; 2012, p. 723-51. doi:10.1016/B978-0-444-53349-4.00157-6.

[3] Pizzi A, Stephanou A. On the chemistry, behavior, and cure acceleration of phenolformaldehyde resins under very alkaline conditions. J Appl Polym Sci 1993;49:215770. doi:10.1002/app.1993.070491212.

[4] Pizzi A, Garcia R, Wang S. On the networking mechanisms of additives-accelerated phenol - Formaldehyde polycondensates. J Appl Polym Sci 1997;66:255-66.

[5] Holopainen T, Alvila L, Rainio J, Pakkanen TT. Phenol- formaldehyde resol resins studied by 13C- NMR spectroscopy, gel permeation chromatography, and differential scanning calorimetry. J Appl Polym Sci 1997;66:1183-93. doi:10.1002/(SICI)10974628(19971107)66:6<1183::AID-APP18>3.3.CO;2-4.

[6] Park B-D, Riedl B, Bae H-J, Kim YS. Differential scanning calorimetry of phenolformaldehyde (PF) adhesives. J Wood Chem Technol 1999;19:2279-89. doi:10.1080/02773819909349612.

400 [7] Pilato L. Phenolic resins: 100Years and still going strong. React Funct Polym 2013;73:270-7. doi:10.1016/j.reactfunctpolym.2012.07.008. phloroglucinol, and pyrogallol as model compounds of flavonoid A- and B- rings with formaldehyde. J Appl Polym Sci 1979;24:1571-8. doi:10.1002/app.1979.070240618.

409 [10] Astarloa Aierbe G, Echeverría JM, Martin MD, Etxeberria AM, Mondragon I. 410 Influence of the initial formaldehyde to phenol molar ratio (F/P) on the formation of a 
phenolic resol resin catalyzed with amine. Polymer (Guildf) 2000;41:6797-802. doi:10.1016/S0032-3861(00)00044-6.

[11] Astarloa-Aierbe G, Echeverría JM, Vázquez A, Mondragon I. Influence of the amount of catalyst and initial $\mathrm{pH}$ on the phenolic resol resin formation. Polymer (Guildf) 2000;41:3311-5. doi:10.1016/S0032-3861(99)00519-4.

[12] Grenier-Loustalot MF, Larroque S, Grande D, Grenier P, Bedel D. Phenolic resins: 2. Influence of catalyst type on reaction mechanisms and kinetics. Polymer (Guildf) 1996;37:1363-9. doi:10.1016/0032-3861(96)81133-5.

[13] Zamfirova G, Cherneva S, Gaydarov V, Djourelov N. Nanocomposites based on epoxy resin. Simulation of microindentation process. Colloids Surfaces A Physicochem Eng Asp 2014;460:254-64. doi:10.1016/j.colsurfa.2014.03.056.

[14] Gabilondo N, Martín MD, Mondragon I, Echeverría JM. Polymerization of formaldehyde and phenol at different pressures. High Perform Polym 2002;14.

[15] Park BD, Wang XM. Thermokinetic behavior of powdered phenol-formaldehyde (PPF) resins. Thermochim Acta 2005;433:88-92. doi:10.1016/j.tca.2005.02.016.

[16] Park BD, Kadla JF. Thermal degradation kinetics of resole phenol-formaldehyde resin/multi-walled carbon nanotube/cellulose nanocomposite. Thermochim Acta 2012;540:107-15. doi:10.1016/j.tca.2012.04.021.

[17] Bessire BK, Minton TK. Decomposition of Phenolic Impregnated Carbon Ablator (PICA) as a Function of Temperature and Heating Rate. ACS Appl Mater Interfaces 2017;9:21422-37. doi:10.1021/acsami.7b03919.

[18] Kershaw D, Still RH, Bashford VG. Thermal degradation of polymers. IX. Ablation studies on composites: Comparison of laboratory test methods with tethered rocket motor firings. J Appl Polym Sci 1975;19:983-98. doi:10.1002/app.1975.070190407.

[19] Natali M, Kenny JM, Torre L. Science and technology of polymeric ablative materials for thermal protection systems and propulsion devices: A review. Prog Mater Sci 2016;84:192-275. doi:10.1016/j.pmatsci.2016.08.003.

[20] Agency EC. Annex VI of Regulation (EC) No 1272/2008 (CLP Regulation). 2015. 
[21] Pilato L. Phenolic Resins: A Century of Progress. 2010.

440

[22] Smith M, March J. Advanced Organic Chemistry: Reactions, Mechanisms and structure. vol. 4.Ed. 1991.

[23] Pizzi A, Mittal KL. Handbook of Adhesive Technology. second ed. n.d.

[24] Foyer G, Chanfi BH, Virieux D, David G, Caillol S. Aromatic dialdehyde precursors from lignin derivatives for the synthesis of formaldehyde-free and high char yield phenolic resins. Eur Polym J 2016;77:65-74. doi:10.1016/j.eurpolymj.2016.02.018.

[25] Simmons KE, Williams JE. Oxidation of p-xylene to terephthalaldehyde. US4017547A, 1977.

[26] Boukis AC, Llevot A, Meier MAR. High Glass Transition Temperature Renewable Polymers via Biginelli Multicomponent Polymerization. Macromol Rapid Commun 2016;37:643-9. doi:10.1002/marc.201500717.

[27] Gabilondo N, López M, Ramos JA, Echeverría JM, Mondragon I. Curing kinetics of amine and sodium hydroxide catalyzed phenol-formaldehyde resins. J Therm Anal Calorim 2007;90:229-36. doi:10.1007/s10973-006-7747-3.

[28] Wang J, Laborie MPG, Wolcott MP. Comparison of model-free kinetic methods for modeling the cure kinetics of commercial phenol-formaldehyde resins. Thermochim Acta 2005;439:68-73. doi:10.1016/j.tca.2005.09.001.

[29] Lee YK, Kim DJ, Kim HJ, Hwang TS, Rafailovich M, Sokolov J. Activation energy and curing behavior of resol- and novolac-type phenolic resins by differential scanning calorimetry and thermogravimetric analysis. J Appl Polym Sci 2003;89:2589-96. doi:10.1002/app.12340.

[30] He G, Riedl B, Aït-Kadi A. Model-free kinetics: Curing behavior of phenol formaldehyde resins by differential scanning calorimetry. J Appl Polym Sci 2003;87:433-40. doi:10.1002/app.11378.

[31] He G, Riedl B, Aït-Kadi A. Curing process of powdered phenol-formaldehyde resol resins and the role of water in the curing systems. J Appl Polym Sci 2003;89:1371-8. doi:10.1002/app.12417. 
[32] Tejado A, Kortaberria G, Labidi J, Echeverria JM, Mondragon I. Isoconversional kinetic analysis of novolac-type lignophenolic resins cure. Thermochim Acta 2008;471:80-5. doi:10.1016/j.tca.2008.03.005.

[33] Lei Y, Wu Q. Cure kinetics of aqueous phenol-formaldehyde resins used for oriented strandboard manufacturing: Effect of wood flour. J Appl Polym Sci 2006;102:3774-81. doi:10.1002/app.24739.

[34] Vyazovkin S, Burnham AK, Criado JM, Pérez-Maqueda LA, Popescu C, Sbirrazzuoli N. ICTAC Kinetics Committee recommendations for performing kinetic computations on thermal analysis data. Thermochim Acta 2011;520:1-19. doi:10.1016/j.tca.2011.03.034.

[35] Vyazovkin S, Chrissafis K, Di Lorenzo ML, Koga N, Pijolat M, Roduit B, et al. ICTAC Kinetics Committee recommendations for collecting experimental thermal analysis data for kinetic computations. Thermochim Acta 2014;590:1-23. doi:10.1016/j.tca.2014.05.036.

[36] Vyazovkin S. A time to search: finding the meaning of variable activation energy. Phys Chem Chem Phys 2016;18:18643-56. doi:10.1039/C6CP02491B.

[37] Friedman HL. Kinetics of thermal degradation of char-forming plastics from thermogravimetry. Application to a phenolic plastic. J Polym Sci Part C Polym Symp 1964;6:183-95. doi:10.1002/polc.5070060121.

[38] Vyazovkin S. Model-free kinetics. J Therm Anal Calorim 2006;83:45-51. doi:10.1007/s10973-005-7044-6.

[39] Vyazovkin S, Dollimore D. Linear and Nonlinear Procedures in Isoconversional Computations of the Activation Energy of Nonisothermal Reactions in Solids. J Chem Inf Model 1996;36:42-5. doi:10.1021/ci950062m.

[40] Corezzi S, Fioretto D, Santucci G, Kenny JM. Modeling diffusion-control in the cure kinetics of epoxy-amine thermoset resins: An approach based on configurational entropy. Polymer (Guildf) 2010;51:5833-45. doi:10.1016/j.polymer.2010.09.073.

[41] Granado L, Kempa S, Bremmert S, Gregoriades LJ, Brüning F, Anglaret E, et al. Isothermal DSC Study of the Curing Kinetics of an Epoxy/Silica Composite for 
Microelectronics. J Microelectron Electron Packag 2017;14:45-50. doi:10.4071/imaps.359903.

498

499

500

501

502

503

504

505

506

507

508

509

510

511

512

513

[42] Rivero G, Pettarin V, Vázquez A, Manfredi LB. Curing kinetics of a furan resin and its nanocomposites. Thermochim Acta 2011;516:79-87. doi:10.1016/j.tca.2011.01.022.

[43] Šesták J, Berggren G. Study of the kinetics of the mechanism of solid-state reactions at increasing temperatures. Thermochim Acta 1971;3:1-12. doi:10.1016/00406031(71)85051-7.

[44] Park B, Riedl B, Kim YSOO, So WONTEK. Effect of Synthesis Parameters on Thermal Behavior of Phenol - Formaldehyde Resol Resin 2001:1415-24. doi:10.1002/app.2302.

[45] Alonso M V., Oliet M, García J, Rodríguez F, Echeverría J. Gelation and isoconversional kinetic analysis of lignin-phenol-formaldehyde resol resins cure. Chem Eng J 2006;122:159-66. doi:10.1016/j.cej.2006.06.008.

[46] Samuelsson LN, Moriana R, Babler MU, Ek M, Engvall K. Model-free rate expression for thermal decomposition processes: The case of microcrystalline cellulose pyrolysis. Fuel 2015;143:438-47. doi:10.1016/J.FUEL.2014.11.079. 


\section{Fig. captions}

515 Fig. 1 - The two main routes to synthetize PF thermosets: Novolac and Resole.

516 Fig. 2 - Probable reactions of pre-polymerization and curing between phenol and

517 terephthalaldehyde.

518 Fig. 3 - DSC thermograms after baseline corrections PF and PTPA.

519 Fig. 4 - Non-isothermal kinetics profiles, inset: reaction rate as function of degree of curing.

520 Fig. 5 - Activation energy of phenol-formaldehyde (PF) and phenol-terephthalaldehyde

521 (PTPA) as a function of the degree of curing as calculated with Vyazovkin (VA) and

522 Friedman (FR) isoconversional methods.

523 Fig. 6 - Arrhenius plots of the Friedman method for PF and PTPA curing systems. Insets

524 display the determination coefficients of linear regressions, as a function of the degree of 525 curing.

526 Fig. 7 - Model-fitting with SB model for PF and PTPA resins. For PTPA, SB model is fitted 527 on the deconvoluted peaks.

528 Fig. 8 - Comparison of predicted and measured isothermal kinetic profiles, at $160{ }^{\circ} \mathrm{C}$, of PF $529 \quad\left(\mathrm{R}^{2}>0.99\right)$ and PTPA $\left(\mathrm{R}^{2}>0.98\right)$ resin.

\section{Table captions}

531 Table 1 - Comparison of properties between PF and PTPA networks [24].

532 Table 2 - Total enthalpy and peak maximum as measured by DSC for PF and PTPA.

533 Table 3 - Kinetic parameters of PF and PTPA as determined with the model-fitting approach 534 (with associated uncertainties of the fits). 